\title{
Rapid Transformation of the Higher Education Sector and Graduate Productivity in the Ugandan labor Market
}

\author{
Edith Mbabazi, ${ }^{*}$ Godfrey Bagonza, Maria Goretti Kaahwa \\ Faculty of Education, Kyambogo University, Kampala, Uganda \\ *Corresponding author: gbagonza@live.co.uk
}

\begin{abstract}
This study investigated the relationship between the rapid and continuous growth of the Higher Education Sector and graduate productivity in the Ugandan Labor Market. The study was guided by three objectives, namely; to find out how rapid transformation of the HE sector is related to graduates' confidence at their places of work; to establish how rapid transformation of the HE sector is related to graduates' timely accomplishment of tasks and to examine how rapid transformation of the HE sector in Uganda is related to graduates ability to work in a team. The study employed a correlational cross-sectional survey design; both quantitative and qualitative approaches were adopted for data collection and analysis from the targeted sample of 90 university lecturers, 6 deans of faculties and schools, 12 heads of departments as well as 3 HR managers. Results revealed a positive significant correlation between rapid transformation of the HE sector and graduates productivity. The study also established that universities are greatly lacking in the quality of training resources. The study concludes that improving the quality of university facilities will improve teaching and learning efficiency which in turn will enhance the quality of university graduates.
\end{abstract}

Keywords: Rapid transformation, higher education, graduates' productivity, labor market, Quality

\section{Introduction}

For over one decade (1996-2019), Uganda has experienced a rapid growth of the higher education sector which is indicated by the increase in the number of students looking for university places as well as the growth in the number of both public and private universities (Kasozi 2006; Mamdani 2007; Muwagga 2011, \& NCHE 2016). The role of university education is to equip students with skills and knowledge that guarantee a specialised workforce for the nation. This study therefore, examined how rapid expansion and transformation of the higher education sector in Uganda is related to graduates' productivity in the world of work.

This expansion and transformation should lead to the development of skills and human capital which are the backbone of economic prosperity and social wellbeing in the $21^{\text {st }}$ century (OECD, 2012). Therefore, nations have to focus on the type of higher education which develops a skilled workforce that meets the labour market demands. In Uganda, this swift expansion of the sector seems to have affected both input and products of higher education. Some studies have suggested that most university graduates who join the labour market lack productive skills required by their new jobs (IUCEA, 2014).

In this study the variable rapid transformation of the higher education sector is conceptualized as the continuous changes in the higher education sector. The transformation is characterized by increased numbers of higher education institutions, raising numbers of students' enrolment causing lecture room congestion, introduction of new academic program and increased costs of higher education. This transformation has been hasty and not properly planned which has constrained the learning environment and affected delivery of the higher education curriculum (Kasozi 2006).

Productivity in general is defined as the quantity and quality of outputs delivered per unit of input utilised that includes labour, capital services and purchased inputs (Chevalier \& Dalton, 2005). Graduate productivity therefore denotes the benefits that employers and institutions derive from their newly acquired graduate employees in relation to the cost 
that they incur on them. Studies by UNESCO (2015) and UNICEF (2014) suggest that indicators of graduate productivity include the way graduates relate with their co-workers, their attitudes towards assigned tasks and how timely they accomplish their assigned tasks. This study conceptualised graduate productivity from the perspectives of their confidence in the world of work, timely accomplishment of tasks assigned to them and willingness to work in a team.

Theoretically, this study was guided by the human capital theory as advanced by Theodore Shultz in 1961, which suggests that individuals and nations spend on education in order to take advantage of better job opportunities that translate into better earnings (Becker, 1993; Joensen, 2009; Nafuko, Haiston and Brooks, 2010). Many scholars also agree that investment in education and training greatly influences growth of individuals' wages, the productivity of organizations and growth of the national economy (Denison, 1962; Shultz, 1961). The theory advocates for practical participation in education and graduates training.

Relatedly Lepark and Snell (1999) show that the firm's competencies or competitive advantage is induced by the investment in human capital entailed with value creating potential, innovations and staff initiatives.

Studies further suggest that individual decisions to pursue higher education involve an informal analysis of the costs of education as measured against the expected value of the returns to that education (Chevalier \& Dalton, 2005;) noted that the human capital theory is based on the idea that education endows individuals with productivity, enhancing human capital and that this productivity results in increased earnings in the labour market.

This view is also supported by the competitive market theory of wages which requires that employees receive a wage which is equal to their marginal product (Marsh \& Hattie, 2002). This also means that the more productive workers are, the more they will be paid, keeping the price of the goods and services constant. This theoretical perspective is important in this study because the rapid transformation and expansion of the higher education sector in Uganda should go hand in hand with the expectations of households and government when they spend money on education. Households and government need to spend money on that type of education which enhances work productivity and generates better returns for both households and government.

Ideally, individuals and parents should spend on higher education in order to take advantage of better job opportunities, increased earnings. It is also widely accepted that quality university education should lead to the acquisition of productive skills, knowledge and other attributes which are of economic value not only to individuals who get lifetime earnings but also to nations and communities which benefit in terms of service delivery and growth in Gross Domestic Product (GDP) (Johnston, 2008; Psacharopoulos, 2008). This is because education is an economic investment that significantly contributes to national development (Fajoju, Oyaziwo \& Ojugo, 2016). Other studies, for example by the Inter-University Council of East Africa, (2014), have indicated that with expansion of the higher education sector, graduates are not well equipped with relevant competencies and productive skills. This study therefore aimed at:

1. Finding out how rapid transformation of the HE sector is related to graduates' confidence at their new places of work.

2. Establishing how rapid transformation of the HE sector is related to graduates' timely accomplishment of tasks.

3. Examining how rapid transformation of the HE sector in Uganda is related to graduates ability to work in a team.

\section{Research Methodology}

This section presents the research methodology used in this study. The section gives the research design and research approaches, study population and sample size, methods of data collection, research procedure and ethical considerations.

\section{The Research Design}

The study engaged correlational and cross-sectional research designs in selection of participants, data collection and data analysis. The design enabled the researchers to establish the direction and magnitude of the relationship between transformation of the higher education sector and graduates' productivity in the Ugandan labour 
market. On the other hand, the cross-sectional research design enabled the investigators to gather data from participants with different characteristics as recommended by authors such as Creswell and Clark (2007), Gorard (2013). In this study, the parameters of the target population included university lecturers, deans of faculties, heads of department and human resource managers from selected employers.

\section{Population and Sampling}

The study population included lecturers, deans of faculties and heads of departments from 3 public universities as well as 3 companies which employ graduates from the three universities. These groups constitute the most important stakeholders representing both universities and employers. Selection of sample size was based the Krejcie and Morgan (1970) table of sample size determination. Distribution of the study population and the sample size are provided in Table 1.

Table 1: Population Size and Sample Size

\begin{tabular}{llll}
\hline Target Category & Population Size & Sample Size & Sampling Method \\
\hline University Lecturers & 723 & 248 & Simple Random Sampling \\
Deans of Faculty & 20 & 06 & Convenience Sampling \\
Heads of Department & 100 & 12 & Convenience Sampling \\
Employment Destinations & 25 & 03 & Convenience Sampling
\end{tabular}

From Table 1, following the Krejcie and Morgan's (1970) table of sample size determination, the researchers sampled 248 respondents out of 723 university lecturers. For the deans, heads of department and employers, convenience sampling was used because information required from them was meant to collaborate and triangulate information from the lecturers.

\section{Methods of data collection}

This study used both quantitative and qualitative approaches for data collection and analysis. These methods were selected because the quantitative approaches enabled collection of data from many respondents within the short period. On the other hand, the qualitative approach was used to collect data that corroborated and triangulated the findings collected by quantitative approaches.

The reliability of the questionnaire was ensured through computing the CVI thus dividing the number of items declared valid with the total number of items. Furthermore, the questionnaire was vetted and refined following Vetter's' remarks to ensure its validity. Thereafter, the instrument was pre-tested and pre-coded in order to measure its applicability. Therefore, internal consistence was achieved. For qualitative data, construct validity was achieved through literature reviewed from multiple sources which provided evidence that the instruments are valid.

\section{Ethical Considerations}

The study sought for approval and obtained clearance from the Research Ethics Committee and Gulu University Research Ethics Committee (GUREC) and the Uganda National Council of Science and Technology (UNCST). The study took into consideration the key ethical issues in social science research which include necessity, non-potentiality for harm, intentionality and confidentiality. For necessity, this study was justified because expansion of the HE sector should put in to consideration the quality of the products. The study was not intended to harm anyone and details of subjects from whom data was collected remained anonymous. The participants were given adequate information in regard to the intentions of the study (Moriaty, 2011).

\section{Findings and Discussion}

Data was coded and analyzed using SPSS. The Spearman Rank Order Correlation (rho) was used to establish the direction and magnitude of the relationship between transformation of the $\mathrm{HE}$ sector and graduates productivity in the Ugandan labor market. This method was preferred because data collected was on an ordinal scale fulfilling the assumptions of the Spearman Rank order correlation analysis. On the other hand, data which was collected by use of interviews was grouped in themes and content analysis was used to analyze 
this data and it was presented according to the study objectives.
Table 2 presents the results of the correlation according to the three hypotheses of the study.

Table 2 Correlation between Rapid Transformation of HE Sector and Graduates' Productivity

\begin{tabular}{|c|c|c|c|c|c|c|}
\hline \multirow[t]{3}{*}{ Rapid transformation of HE sector } & \multicolumn{6}{|c|}{ Indicators of Graduates Productivity } \\
\hline & \multicolumn{2}{|c|}{$\begin{array}{l}\text { Graduates } \\
\text { confidence }\end{array}$} & \multicolumn{2}{|c|}{$\begin{array}{l}\text { Timely } \\
\text { accomplishment } \\
\text { of tasks }\end{array}$} & \multicolumn{2}{|c|}{ Ability to work in a team } \\
\hline & Rho & P-Value & Rho & P-Value & Rho & P-Value \\
\hline Effect on facilities & 0.306 & 0.000 & 0.295 & 0.000 & 0.285 & 0.000 \\
\hline Quality of Lecturers & 0.213 & 0.000 & 0.264 & 0.000 & 0.345 & 0.000 \\
\hline Study Programs in $\mathrm{HE}$ & 0.295 & 0.000 & 0.524 & 0.000 & 0.397 & 0.000 \\
\hline
\end{tabular}

Source: Primary Data. ${ }^{* * *}$ Correlation is significant at the 0.005 level (2-tailed)

Hypothesis 1 stated that 'rapid transformation of the HE sector is not related to graduates' confidence at their new places of work'

Rapid transformation was measured around facilities, quality of lecturers, expansion of study programs and the interest was how these are graduates confidence at the place of work. From Table 2, effects on facilities is related to graduates confidence with a rho $=0.306$ with a P-value of 0.000 . This is significant at the 0.005 level of significance indicating that rapid transformation of the HE sector has an effect on university facilities which in turn affects graduates' confidence in the labor market.

On the other hand the quality of university lecturers is related to graduates confidence with a rho $=0.213$ with $\mathrm{P}$-Value $=0.001$. These findings are also significant at the 0.005 level of significance indicating that the quality of university lecturers affect graduates confidence in the labor market.

When it comes to programs of study which have also increased in universities, Study program is related to graduates' confidence with $r h o=0.295$ and P-Value of 0.000 . These findings are significant at the 0.005 level of significance

These findings are confirmed by the interview with one of the faculty deans of the universities who accepted that rapid transformation of the higher education sector has impacted on the confidence of university graduates. He observed that:

'The higher education sector in Uganda has been subjected to rapid transformation which emanates from social, political and economic pressures. As a result university education has experienced rapid changes, expansion and transformations which have affected the quality of university facilities, the quality of university lecturers and the quality of university programs. The government has succumbed to this pressure and allowed a free market economy and political agitations to take lead which has also impacted on graduates' confidence in the labor, their commitment on assigned tasks, their ability to work in a team and their willingness to stay on job. As such, employers complain about the skills that universities give to make these graduates productive in the labor market' (Dean of Faculty, June 2019).

Hypothesis 2 stated that 'rapid transformation of the HE sector is not related to graduates' timely accomplishment of their tasks.

From Table 2, effect of facilities is related to graduates' accomplishment of their tasks with a rho $=0.295$ with a P-value of 0.000 . This is significant at the 0.005 level of significance meaning that rapid transformation of the HE sector has an effect on university facilities which in turn affects graduates' accomplishment of their assigned tasks. In a related way, quality of university lecturers is related to graduates timely accomplishment of their tasks with a $r$ o $=0.264$ with P-Value $=0.000$. These findings are also significant at the 0.005 level of significance indicating that the quality of university lecturers affect graduates' accomplishment of tasks assigned to them. Therefore, the null hypothesis is rejected.

When it comes to programs of study which have also increased in universities, Study programme is related to graduates' accomplishment of tasks with $r h o=0.524$ and P-Value of 0.000 . These findings are significant at the 0.005 level of significance indicating that increase in programmes of study has affected graduates accomplishment of tasks assigned to them. These findings are supported by information got from an interview with another dean of faculty who noted that: 
'Public universities have been partially liberalized; there are currently private entry schemes that allow students to study in the evening and on weekends. These institutions have fundamentally changed from the nature of the old traditional universities. They have been transformed in terms of structure of the old traditional universities. They have been transformed in terms of structure and composition and this has affected the moral values and ethical issues that graduates take to the field. There is great need to consider how organizational structures such as regulations, policies, norms, cultures and structural routines have been established to guide the conduct of both students and staff in the universities to equip graduates with those values such as punctuality, commitment to duty and timely accomplishment of tasks which are desired in the world of work' (Dean of Faculty, June 2019).

Hypothesis 3 stated that 'rapid transformation of the HE sector is not related to graduates' ability to work in a team.

Team work is one of the most important attributes that enable employees to achieve organizational objectives. From Table 2, effects on facilities is related to graduates' ability to work in a team with a $r h o=0.285$ and a P-value of 0.000 . This is significant at the 0.005 level of significance meaning that rapid transformation of the HE sector has an effect on university facilities which in turn is related to graduates ability to work in a team. In a related way quality of university lecturers is related to graduates' ability to work in a team with a rho $=$ 0.345 and a P-Value $=0.000$. These findings are also significant at the 0.005 level of significance indicating that the quality of university lecturers affect graduates' ability to work in a team. Finally programme of study is correlated to graduates' ability to work in a team with $r h o=0.397$ and Pvalue $=0.000$. These findings are significant at the 0.005 level of significance indicating that increase in programmes of study has affected graduates' ability to work in a team. Therefore, the null hypothesis is rejected.

The findings on the relationship between rapid expansion of the HE sector and graduates' ability to work in a team are supported by information got from interviews with $3 \mathrm{HR}$ managers from 3 employer companies. One these HR managers had this to say:

Universities need to create a conducive learning environment with sufficient facilities which will enable learners to acquire practical skills which are needed by employers. Learners should be helped to develop the capability to compete and win on the labor market, perform well on the job and work in various locations. They should be helped to know that the world of work is highly competitive and students look at higher education as preparation to obtain a better position in the highly competitive labor market. Therefore, universities should endeavor to provide facilities which match the status of employing companies if students are to be confident and impress when they are in employment. (Human Resource Manager, June $16^{\text {th }}$ 2019).

Employers also pointed out that most newly recruited graduates usually indicated that the new jobs did not suit to their personal objectives; and they were unable to apply knowledge they had learnt from the university; and that some were not confident enough to get along with co-workers. Employers also suggested that graduates from technical disciplines like electrical, mechanical, and computer science adjusted easily to their work compared to their counterparts from the arts and the humanities. This could probably be because these are more exposed to practical work in the universities compared to their counterparts from other disciplines.

Asked about what factors made newly recruited graduates not stay long at work and how the school facilities could be contributing to this, most employers pointed out the following factors as common:

1. Newly recruited graduates did not like job offer.

2. Job offer not in their field of specialization.

3. Low salary below their expectations.

4. Job is far from their residence.

5. Hard work conditions than they expected.

Finding on the 3 hypotheses used by this study indicate that there is a significant relationship between rapid transformation of the higher education sector and graduates productivity in the labor market. University inputs such the quality of lecturers, the nature of university facilities, and the type of study programs are related to graduates' productivity in terms of their confidence at work, timely accomplishment of tasks, and ability to work with others.

\section{Conclusion and Recommendations}

This part gives the conclusions and recommendations of the study. 


\section{Conclusions of the Study}

From the findings, the study concludes that:

1. Rapid transformation and expansion of the HE sector are related to graduates confidence when they join the world of work. This is because graduates should have been appropriately prepared to meet the expectations of employers.

2. Rapid transformation and expansion of the higher education sector are related to graduates timely accomplishment of tasks assigned to them. Changes in the higher education sector affect the skills and knowledge which enable graduates to accomplish their tasks.

3. Rapid transformation of the higher education sector is related to graduates ability to work in a team. Graduates who are socialized to work in a team while they are still at university will easily cope with other team member when they join the world of work.

\section{Recommendations of the Study}

From the findings and conclusions, the study recommends that:

1. As the higher education sector expands, institutions should emphasize linkage between the university and employers. Students need to be equipped with skills and knowledge which makes the confident when they join the world of work.

2. Higher learning institutions need to cultivate a culture of hard work, punctuality, and commitment to students. This culture coupled with professional support will enable graduates to achieve their assigned tasks on time.

3. Finally, university students should be encouraged to work in teams and group works should be encouraged. This will help students to develop social skills and communication skills which are required in the world of work.

\section{Reference}

Becker, G. S. (1993), Human capital: a theoretical and empirical analysis with special reference to education. (3rd Ed.). Chicago; London: University of Chicago Press.

Chevalier, A. and Dolton, P. (2005). 'The Labour Market for Teachers'. In S. Machin and A.
Vignoles (Eds), What's the Good of Education? The Economics of Education in the UK. Princeton, N.J. Oxford: Princeton UP.

Creswell, J.W. \& Clark, P.V. (2007). Designing and Conducting Mixed Methods Research. London: Sage Publications Inc.

Fajoju, S.A., Oyaziwo, A., Ojugu, A.I. (2016). 'Parental involvement as Correlates of Academic Achievement in Edo State, Nigeria'. Research in Education, Vol. 95 (1). $33-43$.

Gorard, S. (2013). Research Design: Robust Approaches for Social Sciences. London: Sage Publications Inc.

IUCEA. (2014). Report from a Study Establishing the Status of Higher Education Qualification Systems and their Contributions to Human Resources Development in East Africa. Kampala: IUCEA.

Johnstone, D.B. (2008). Cost Sharing in Higher Education: Tuition, Financial Assistance, and Accessibility in A comparative Perspective. Czech Sociology Review, Vol.39, No.3.

Kasozi, A. B. K. (2006). 'A proposed quality assurance framework for institutions of higher learning in Uganda'. Paper presented at Seminar on quality assurance in tertiary education, June 18-20. Servres, France.

Krejcie R. and Morgan, D. (1970). 'Determination of Sample Size'. Journal of Educational and Psychological Measurement, Vol. 3, (30) 607-610.

Lepak, D.P. \& Snell, S.A. (1999). The Human Resource Architecture: Towards a Theory of Human Capital Allocation and Development. Academy of Management Review.

Mamdani, M. (2007). Scholars in the marketplace: the dilemmas of neo-liberal reform at Makerere University, 1989-2005. Dakar, Senegal: Council for the Development of Economic and Social Research in Africa.

Marsh, H. W. and Hattie, J. (2002). 'The Relation Between Research Productivity and 
Teaching Effectiveness: Complementary, Antagonistic, or Independent Constructs?' The Journal of Higher Education - Volume 73, N0. 5, pp. 603641.

Muwagga, M.A. (2006). The Philosophical Implications of the Liberalization of University Education in Uganda. Doctoral Thesis. Makerere University Kampala.

Nafuko, F.M., Hairston.N. \& Brooks, K. (2010). 'Human Capital Theory: Implications for Human Resource Development'. Human Resource Development International.

National Council for Higher Education. (2006), The state of Higher Education and Training in Uganda 2006. Kampala.
OECD. (2012). 'Assessment of Higher Education Learning Outcomes'. A feasibility Study Report Vol.1 -Design and Implementation. Paris: OECD Publications.

Psacharopoulos, G. \& Patrinos, H.A. (2018). 'Returns to Investment in Education: a Decennial Review of Global Literature'. Education Economics. 26:5, $445-458$.

Schultz, T. W. (1972). Investment in education: the equity-efficiency quandary. Chicago; London: University of Chicago Press.

UNESCO, (2015). Teachers and the Quality of Basic Education in Sub Saharan Africa. Education Research and Foresight working papers.

UNICEF, (2014). A review of evaluations of UNICEF education activities (1994-2015). Paris: UNICEF. 